\title{
Directivity Enhancement of Miniaturized Directional Coupler using Defected Ground Structure
}

\author{
P. Bhakhar ${ }^{1}$, V. Dwivedi ${ }^{2}$ and P. Prajapati ${ }^{3}$ \\ ${ }^{1}$ Department of E C Engineering, Faculty of Technology, C.U. Shah University, Wadhwan City, Gujarat, India \\ ${ }^{2}$ C. U. Shah University, Wadhwan City, Gujarat, India \\ ${ }^{3}$ A D Patel Institute of Technology, Vallabh Vidyanagar, Gujarat, India \\ \{praful.bhakhar@bvmengineering.ac.in ${ }^{1}$; provc.cushahuniv@gmail.com² ${ }^{2}$ pravinprajapti05@gmail.com ${ }^{3}$ \}
}

\begin{abstract}
This research paper investigates about the novel approach in the design and analysis of Couplers operating at $5 \mathrm{GHz}$, which finds its application for next generation communication systems. The concept of Defected Ground Structure (DGS) in the design of planar coupler is useful for next generation communication systems. The Planar Coupler with an embedded DGS structure is designed for an operating frequency $5 \mathrm{GHz}$. A convention allow profile planar coupler with an embedded a head dumbbell shaped DGS structure operating at 5 $\mathrm{GHz}$ was designed independently and integrated embedded with resonating DGS. The analysis is carried out by varying the dimensions of the DGS. Various electrical performance parameters like transmission coefficient, return loss, coupling factor and isolation have been analytically observed and reproduced for aspirant researchers and designers. The integration of this electromagnetically coupled DGS resulted into significant volumetric reduction of the directional coupler. Incorporating one circular head dumbbell shape reduces the size of ground plane up to $31 \%$ while we achieved reduction of $12 \%$ in strip-length in comparison to the equivalent conventional coupler. In addition, we found an increase of $127.27 \%$ in its directivity compared to conventional counterpart. The effects of variations of DGS dimensions on scattering parameters of this coupler have shown appreciable enhancement. This coupler helps as an inspiration, encouragement and motivation for saving the materials used in designing it, reduces the electrical and RF losses converted into heat and thus a journey towards go-green-earth!
\end{abstract}

Keywords: Coupler, DGS, Directivity.

\section{Introduction}

A directional coupler is a four-port microwave passive device in which the energy passing through is coupled from one transmission line to the other. The usual techniques for directional coupler have two transmission lines with some mechanism for coupling between them. Directional couplers divide signals based on the direction of their propagation. The directional couplers are widely used in impedance bridges for microwave measurements, power combiners, power splitters, power monitors, and attenuators, transreceiver [1]. The progresses in modern communication systems are imposing new requirements, such as compact size, broadband, and multiple band operations, for the design of the passive circuits [2-5]. To fulfill these types of requirements, performance parameters of the power divider sand couplers, as an important passive component, needs to be improved.

Numerous methods have been developed to reduce the size of a rat-race coupler with various configurations. Meandering of transmission lines [6] or coupled lines [7] are well-known methods of miniaturization. Microstrip transmission lines are implemented for the miniaturization and harmonic suppression in planar rat-race couplers [8]. Using space-filling characteristics of the fractal curves, the size of the rat race coupler has been reduced [9]. Size reduction in a fractal, rat-race coupler is achieved by changing the fractal iteration, which poses a problem of implementing the impedance transformers at ports, making the actual rat-race coupler size larger than $12.6 \%$ of the conventional case as reported. Another way to reduce the size of the rat-race coupler is using periodical open stubs directed inside the ring [10], which reduces the occupied area to $33 \%$ of a conventional rat-race coupler. Nowadays DGS has drawn an increasing interest in antennas and microwave circuits $[11,12]$. DGS have found numerous applications in the design of microwave circuits, such as antennas, couplers, amplifiers, and filters [13-15]. DGS shapes inserted in the ground plane of the transmission lines add the equivalent capacitive and inductive elements to transmission lines, which modify the characteristic impedance and effective dielectric constant, and slow-wave effect produced [16]. The additional lumped inductance added because of DGS plays major role to reduce the phase velocity of the wave, which leads to generation of the slow wave

B. Iyer, S. Nalbalwar and R.Pawade(Eds.)

ICCASP/ICMMD-2016. Advances in Intelligent Systems Research.

Vol. 137, Pp. 739-746.

(C) 2017- The authors. Published by Atlantis Press

This is an open access article under the CC BY-NC license (http://creativecommons.org/licens)es/by-nc/4). 
effect. The slow wave factor is given by the ratio of (propagation constant) and (free space wave number). Because of this effect, the effective electric length of the planar microwave device increases, due to which overall size of the coupler reduced.

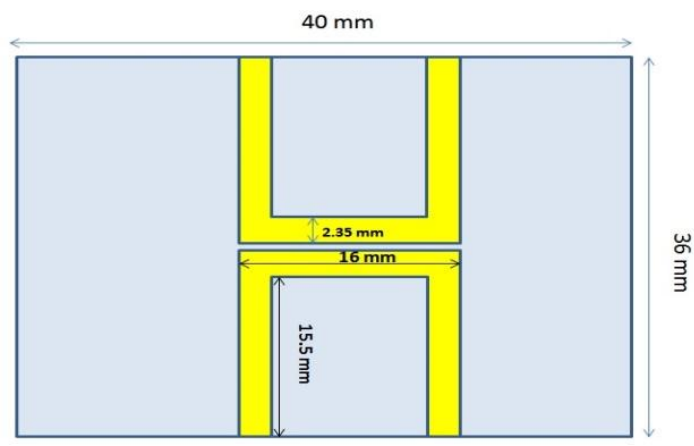

Fig. 1. Geometry of the proposed directional coupler

In this paper, optimal design of branch line coupler with DGS is presented, which reduces the size of the conventional coupler. Slow-wave effect caused by the equivalent LC components is one of the advantages of DGS. With compared to the conventional lines, the transmission lines integrated with DGS having much higher impedance and increased slow wave factor which helps the reduction of the circuit [17].

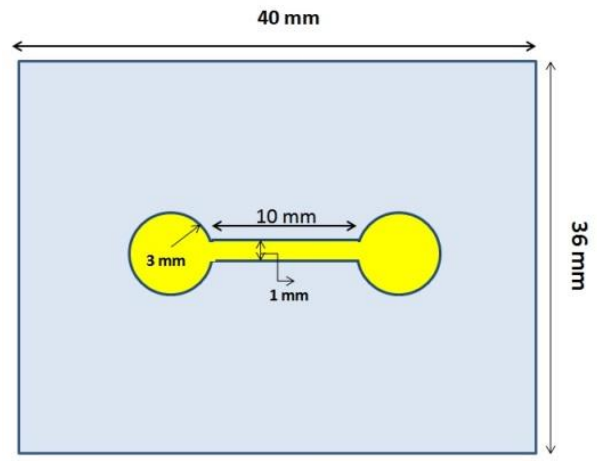

Fig. 2. Design dimensions of the proposed DGS

\section{Design of Proposed Coupler}

The geometry of the proposed uniplanar coupler with design dimension is shown in Fig. 1. This circuit model is designed using an RF substrate having a dielectric constant of 4.4, loss tangent of 0.0025 , and thickness of 1.524 $\mathrm{mm}$. The circuit design of the proposed coupler has single-layer construction without any bond wires.

\subsection{Design of DGS}

The DGS is realized by etching a certain shape in the ground plane of micro-strip line. DGS shapes such as rectangular, arrow head, square head, spiral, etc. has been reported by researchers to improve figure of merit of antennas, couplers, filters, etc. The proposed circular head dumbbell shape DGS, its dimensions and locations are shown in Fig. 2. DGS adds the equivalent capacitive and inductive elements to transmission lines, and thus modify the characteristic impedance and effective dielectric constant, slow-wave effect produced. DGS is also used to reject a certain frequency band of the micro-strip circuit. General approach of representing a DGS in terms of equivalent parallel LC or RLC circuit is shown in Fig. 3. This figure shows the equivalent circuit of dumbbell DGS. The larger rectangular defect on either side of the line causes the effective series inductance $\mathrm{L}$ or the narrow slot beneath the line produces a gap capacitance $\mathrm{C}$ in parallel with $\mathrm{L}$. The value of $\mathrm{L}$ and $\mathrm{C}$ are given by [18],

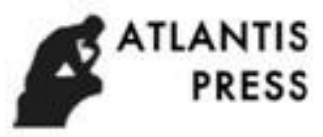




$$
\begin{aligned}
& C=\frac{\omega_{c}}{2 z_{0}^{2}\left(\omega_{0}^{2}-\omega_{c}^{2}\right)} \\
& L=\frac{1}{4 \pi^{2} f_{0}^{2} C}
\end{aligned}
$$

Where $\omega_{0}=$ angular resonant frequency, $f_{0}=$ resonant frequency, $\omega_{\mathrm{c}}=$ cut-off frequency, $\mathrm{Z}_{0}=$ Characteristic impedance.

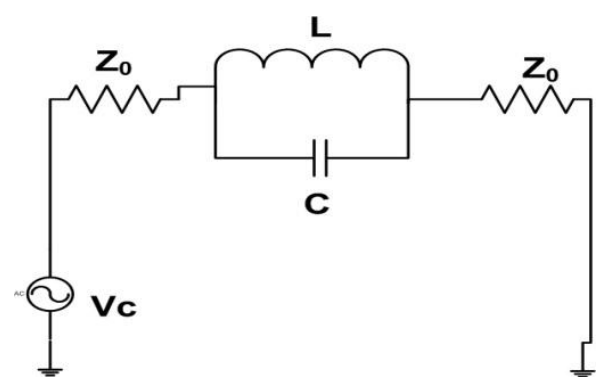

Fig. 3. LC equivalent circuit of single cell dumbbell-shaped DGS [14]

\subsection{Effect of DGS on characteristics impedance}

The DGS etched below the micro-strip line introduces additional effective inductance, which increases the characteristic impedance of the micro-strip line. Thus, the resultant characteristic impedance of the micro-strip line is much higher than that of the conventional micro-strip line with the same conductor width, which gives easy fabrication of the micro-stripline.

The scattering parameter $\mathrm{S}_{21}$ depends on the resultant electrical length produce byDGS and can be expressed by [19].

and the variable $\mathrm{m}$ is

$$
S_{21}=\frac{1}{(\operatorname{Cos} \theta+j m \operatorname{Sin} \theta)}
$$

$$
m=\frac{1}{2}\left(\frac{Z_{0}}{Z_{c}}+\frac{Z_{c}}{Z_{0}}\right)
$$

The constant $\theta$ is the electrical length. The value of $m$ and $\theta$ can be derived from the magnitude $\left|\mathrm{S}_{21}\right|$ and phase $\left|\phi_{21}\right|$ of $\left|S_{21}\right|$ and is given by

$$
m=\arctan \left(\frac{1}{m} \tan \phi_{21}\right)+n \pi, \text { where } n=0,1,2
$$

Then, the equation of characteristics impedance is

$$
\begin{aligned}
& Z_{c}=Z_{0}\left(m+\sqrt{m^{2}-1}\right), Z_{c}>Z_{0} \\
& Z_{c}=Z_{0}\left(m-\sqrt{m^{2}-1}\right), Z_{c}<Z_{0}
\end{aligned}
$$

From this equation, it can be concluded that the effective characteristics impedance of the micro-strip line can be adjusted by changing the dimensions of the DGS.

\section{Parametric Studies}

This section focuses on the effects of various parameters of DGS in this coupler. Change in circular head dumbbell DGS parameter affects the resonant frequency of the coupler. The effect of variation of the radius of circular head of dumbbell shape DGS on $\mathrm{S}_{11}$ (return loss) of the proposed coupler is shown in Fig. 4. As we change 
the radius of DGS, the resonant frequency of coupler is shifted towards left. That means size is reduced. The larger radius of the circular head dumbbell DGS creates slower wave effect, due to this, the resonance frequency of the coupler reduced. Here, optimum radius $(\mathrm{R}=3 \mathrm{~mm})$ selected for getting $3 \mathrm{~dB}$ coupling at $5 \mathrm{GHz}$. Fig. 5 shows effect of variation of circular head DGS on coupling $\left(\mathrm{S}_{31}\right)$.It is concluded that by changing the radius of the circular head DGS, $3 \mathrm{~dB}$ coupling frequency can be changed.

The effect of variation of circular-head dumbbell shape DGS on isolation of the proposed coupler is shown in Fig. 6. Even though, with $\mathrm{R}=4 \mathrm{~mm}$, high isolation achieved, with the consideration of other parameters such as $\mathrm{S}_{11}, \mathrm{~S}_{21}, \mathrm{~S}_{31}$, etc. $\mathrm{R}=3 \mathrm{~mm}$ has been selected.

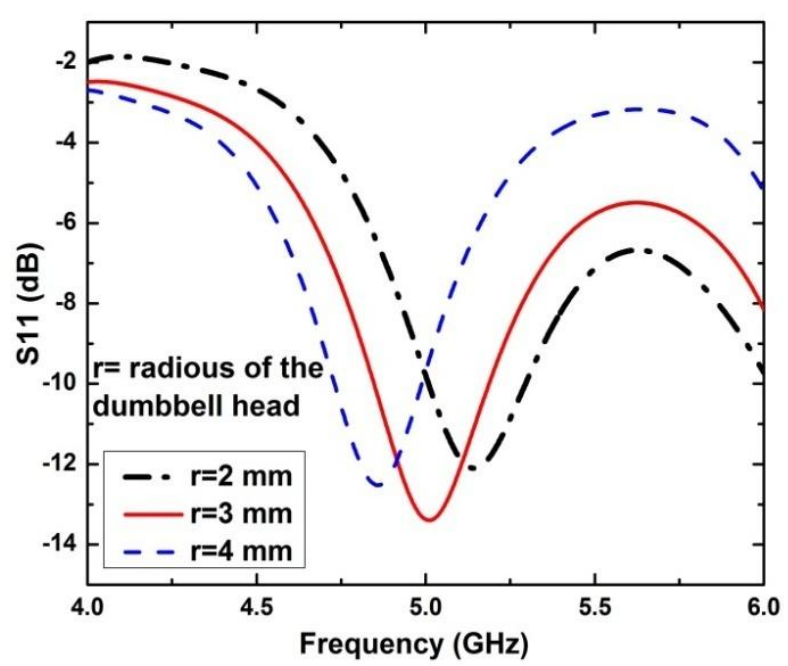

Fig. 4. Effect of variation of DGS circular head radius on return loss of proposed coupler

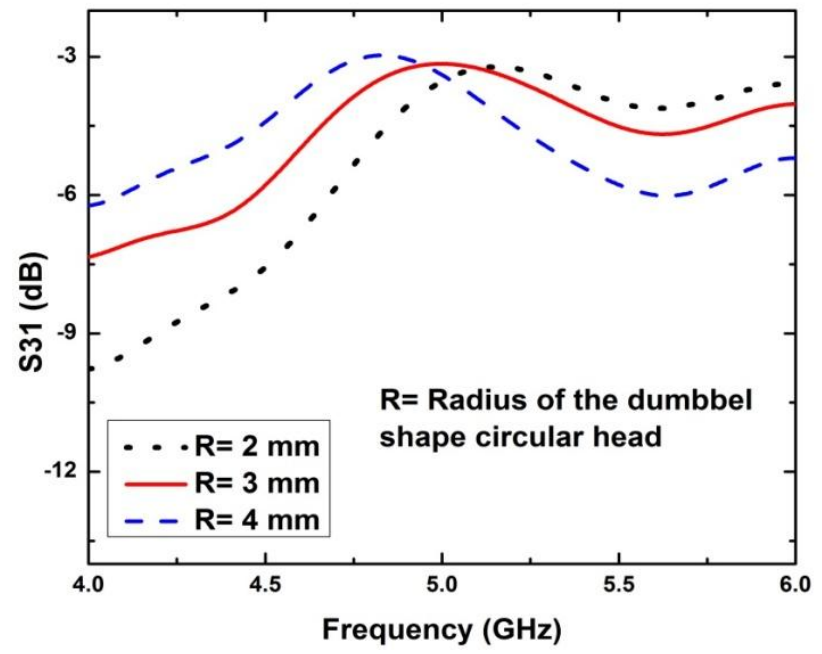

Fig. 5. Effect of variation of DGS circular head radius on coupling factor of proposed coupler

\section{Results}

The design dimensions of proposed coupler have been optimized and analyzed using CST microwave studio V.16 [37], which is commercially available electromagnetic software based on the method of finite difference 
time domain technique. All the important parameters of the coupler such as return loss, transmission coefficient, coupling coefficient and directivity were studied and the simulated results have been presented.

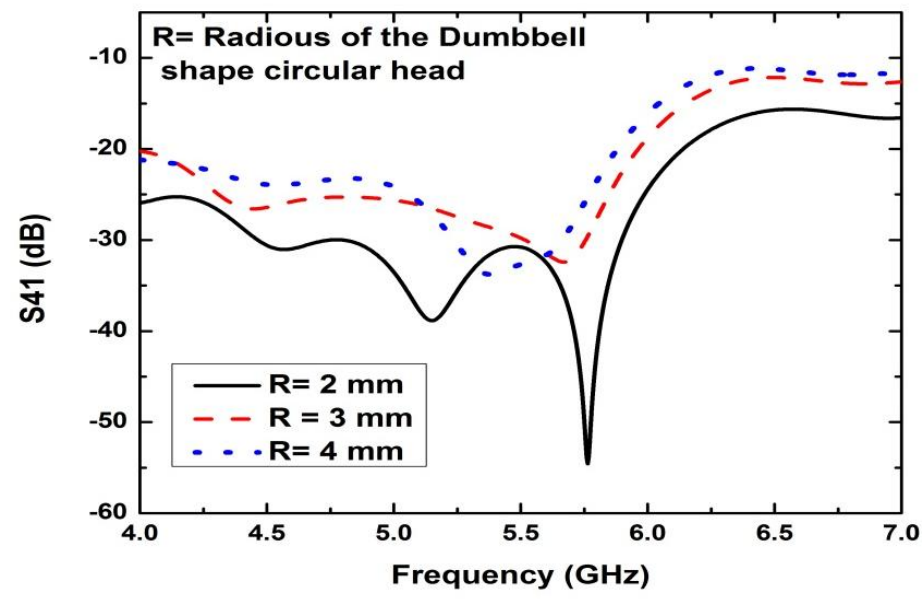

Fig. 6. Effect of variation of DGS circular head radius on isolation of proposed coupler

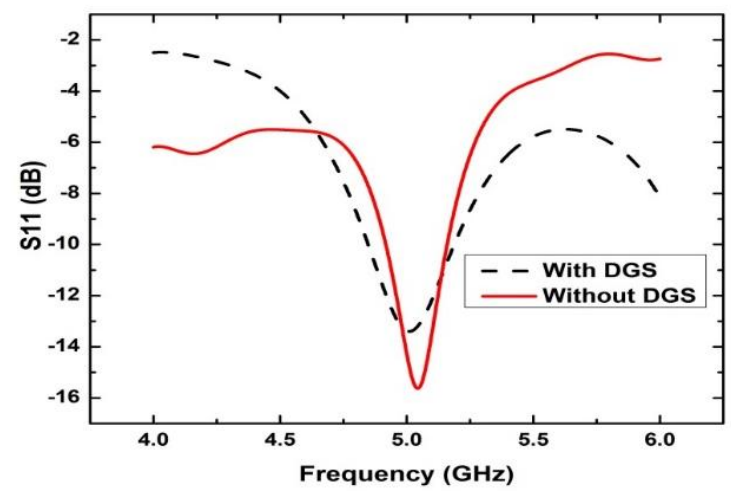

Fig. 7. Comparison of return loss (S11) (with and without DGS) of the proposed coupler

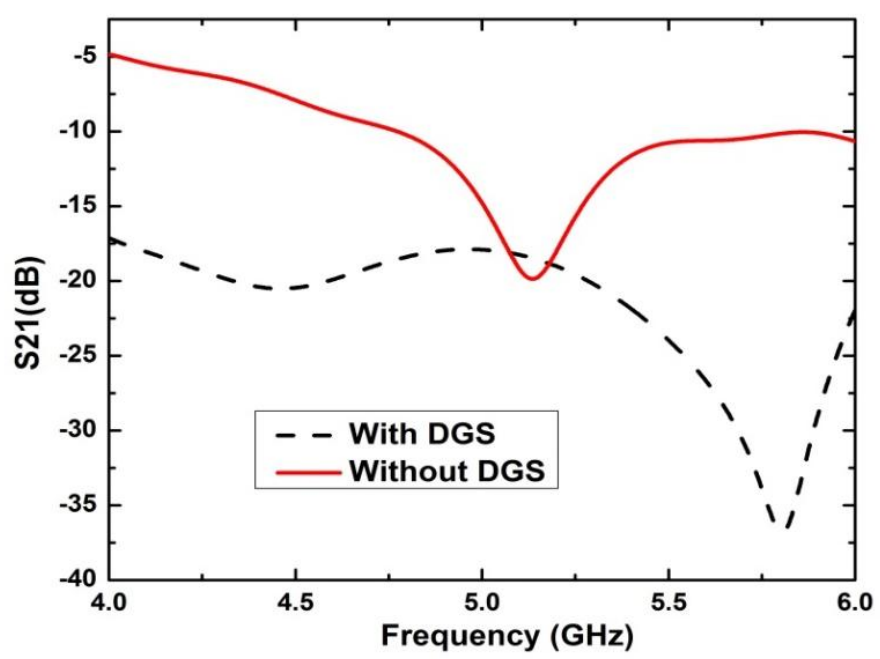

Fig. 8. Comparison of transmission coefficient $\left(\mathrm{S}_{21}\right)$ (with and without DGS) of the proposed coupler. 


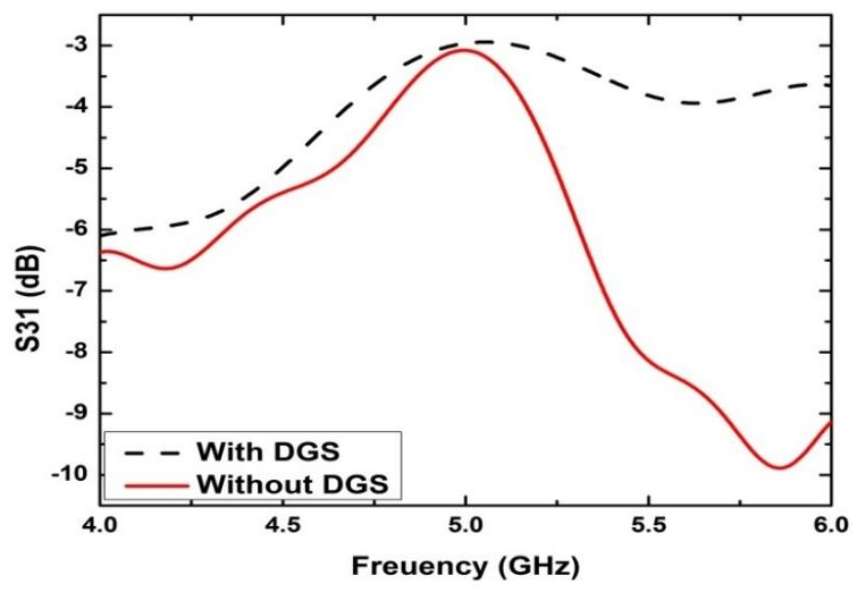

Fig. 9. Comparison of coupling parameter $\left(\mathrm{S}_{31}\right)$ (with and without DGS) of the proposed coupler.

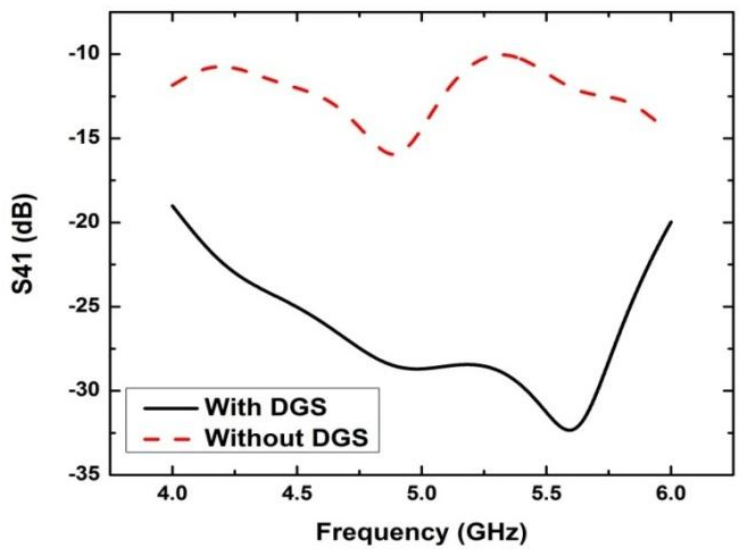

Fig. 10. Comparison of isolation parameter $\left(\mathrm{S}_{41}\right)$ (with and without DGS) of the proposed coupler.

Scattering parameters of the directional coupler without DGS and with DGS are shown in Figs. 7 to 10 . The operating frequency of the proposed coupler is $5 \mathrm{GHz}$. After incorporating DGS, resonant frequency is shifted towards left due to slow wave effect. That means a size reduction is achieved. As shown in Fig. 7 and Fig. 8, not much changes in return loss as well as in transmission coefficient respectively after the incorporation of DGS. This means in this design, there is no much effect of integration of the DGS on return loss and transmission coefficient of the coupler. It was observed in simulation results that after integrating DGS in the ground plane of the coupler, more flat curve of $\left(\mathrm{S}_{31}\right)$, i.e. more uniform coupling at $5 \mathrm{GHz}$ obtained as compared to without DGS as shown in Fig. 9.

As shown in Fig. 10, isolation of the conventional coupler without DGS is $14 \mathrm{~dB}$. To couple power in specific branch and for precise transmit power monitoring, the directivity and insertion loss (IL) are the two most important performance parameters of any coupler. For enhancement of the directivity, various methods such as using reactive loading methods [20-24], reflected power cancellation [25-27], spur-line utilization, metamaterial [28], negative refractive index line [34], etc. have been reported.

In our propose design, with the incorporation of DGS, equality in the each mode, velocity is achieved due to the slow wave effect of DGS and isolation of the coupler improves from $14 \mathrm{~dB}$ to $28 \mathrm{~dB}$, which leads to the enhancement of the directivity by $127.27 \%$. Comparison between proposed work with earlier reported work on size reduction and directivity enhancement in coupler are illustrated in Table I. It shows that, earlier reported techniques capable only either size reduction or directivity enhancement. Using optimized DGS, it is possible to obtain both desirable characteristics. 
Table 1. Comparison between proposed works with earlier reported work

\begin{tabular}{|c|c|c|c|}
\hline Ref. no. & Technique used & $\%$ Size reduction & Directivity Enhancement \\
\hline$[29]$ & Fractal shunt stub & $81.5 \%$ & no enhancement \\
\hline$[30]$ & Quasi fractal loaded structure & $78 \%$ & no enhancement \\
\hline$[31]$ & $\begin{array}{c}\text { Left handed } \\
\text { Structure }\end{array}$ & $75 \%$ & no enhancement \\
\hline$[32]$ & Right/left handed unit cell & $50 \%$ & $30 \mathrm{~dB}$ \\
\hline$[33]$ & Bypass circuit & no reduction & $45 \mathrm{~dB}$ \\
\hline$[34]$ & $\begin{array}{c}\text { Negative refractive index tech- } \\
\text { nique }\end{array}$ & no reduction & $40 \mathrm{~dB}$ \\
\hline$[35]$ & Epsilon negative transmission line & no reduction & $48 \mathrm{~dB}$ \\
\hline$[36]$ & Loaded with shunt inductor & no reduction & $\begin{array}{c}25 \mathrm{~dB} \text { i.e. } \\
\text { ment })\end{array}$ \\
\hline $\begin{array}{c}\text { Our proposed } \\
\text { work }\end{array}$ & Loaded with DGS & $\begin{array}{c}12 \% \text { reduction in strip } \\
\text { length }\end{array}$ & $\begin{array}{c}(127.27 \% \text { directivity enhance- } \\
\text { meduction in ground }\end{array}$ \\
\hline
\end{tabular}

\section{Conclusions}

This paper presents the application of DGS in the design of planar coupler. The integration of DGS reduces the size of the branch line coupler. It is observed that the inclusion of DGS structure resulted in $12 \%$ of size reduction in strip length as well as $31 \%$ in ground size is achieve. In the design, DGS plays major role to compensate inequality in the each mode velocity of the hybrid coupler. By using DGS, $127.27 \%$ directivity enhancement is achieved. The effect of different shapes of DGS such as spiral, H-shape, V shape, circular head dumbbell, arrow head dumbbell, may be the future scope of this work.

\section{References}

[1] Brijesh Iyer, A. Kumar, N P. Pathak, "Design and analysis of subsyetems for concurrent dual-band transreceiver for WLAN applications," Proc. of Int. conf. on Signal Proc. and Communi. (ICSC-13), 57-61 Noida, India (2013).

[2] Brijesh Iyer, N.P.Pathak and D.Ghosh, "Reconfigurable Multiband Concurrent RF System For NonInvasive Human Vital Sign Detection”, 2014 IEEE Region 10 Humanitarian Technology Conference (R10 HTC), Chennai, India, Aug. 2014, pp.111-116.

[3] Brijesh Iyer, A.Kumar, N.P.Pathak and D.Ghosh, "Concurrent multi-band RF system for search and rescue of human life during natural calamities", IMaRC-2013, New Delhi, India, Dec. 2013, pp.1-4.

[4] Brijesh Iyer, M.Garag, N.P.Pathak and D.Ghosh, "Contactless Detection and Analysis of Human Vital Signs Using Concurrent Dual-Band RF System”, Procedia Engineering,vol.64, pp.185-194, 2013

[5] Brijesh Iyer, N.P Pathak, D Ghosh, "RF sensor for smart home application", International Journal of System Assurance Engineering and Management, May-2016, doi: 10.1007/s13198-016-0468-5.

[6] E. G. Cristal, "Meander-line and hybrid meander-line transformers," IEEE Trans. Microw. Theory Tech., 21, 69-76, (1973).

[7] H. Tanaka, Y. Sasaki, T. Hashimoto, Y. Yagi, and Y. Ishikawa, "Miniaturized $90^{\circ}$ hybrid coupler using high dielectric substrate for QPSK modulator," IEEE MTT-S IntMicrow. Symp. Dig., Baltimore, MD, 793-796, (1996).

[8] M. L. Chuang, "Miniaturized ring coupler of arbitrary reduced size," IEEE Microw. Wireless Compon. Lett., 15, 16-18, (2005).

[9] H. Ghali and T. A. Moselhy, "Miniaturized fractal rat-race, branch line and coupled-line hybrids," IEEE Trans. Microw. Theory Tech., 52, 2513-2520, (2004).

[10] K. W. Eccleston and S. H. M. Ong, "Compact planar micro-strip line branch-line and rat-race couplers,” IEEE Trans. Microw. Theory Tech., 51, 2119-2125, (2003).

[11] A. K. Arya, M. V. Kartikeyan, A. Patnaik, "Defected ground structure in the perspective of micro-strip antennas: A review,” Frequenz Int. J. of RF Engg. and Telecom., 64, 79-84, (2010).

[12] P. R. Prajapati, G. G. K. Murthy, A. Patnaik, and M. V. Kartikeyan, "Design and testing of a compact circularly polarized microstrip antenna with fractal defected ground structure for L-band applications," IET Microw. Antennas and Propag., vol. 9, 1179-1185, (2015). 
[13] D. Ahn, J. S. Park, C. S. Kim, J. Kim,, Y. Qian,, and T. Itoh, "A design of the low-pass filter using the novel micro-strip defected ground structure," IEEE Trans. Microw. Theory and Techn., 49, 86-93, (2001).

[14] Y. J. Sung, C. S. Ahn, and Y. S. Kim, "Size reduction and harmonic suppression of rat-race hybrid coupler using defected ground structure," IEEE Microw. Wireless Component Lett., 14, 79, (2004).

[15] P. R. Prajapati, A. Patnaik and M. V. Kartikeyan, "Design and characterization of an efficient multilayered circularly polarized micro-strip antenna," Int. J. of Microw. and Wireless Techn., 1-9, (2015).

[16] D. Guha, Y. M. M. Antar, Micro-strip and Printed Antennas: New Trends, Techniques, and Applications, John Wiley and Sons Ltd., (2011).

[17] R. Sharma, T. Chakravarty, S. Bhooshan, and A. B. Bhattacharyya, "Designof a novel 3 dB microstrip backward wave coupler using defected ground structure," Progress In Electromagnetics Research (PIER), 65, 261-273, (2006).

[18] J. I. Park, C. S. Kim, J. Kim, J. S. Park, Y. Qian, D. Ahn, and T. Itoh, "Modelling of a photonic bandgap and its application for the low pass filter design," Proc. of Asia Pacific Microwave Conf., 331-334, (1999).

[19] T. Moyra, S. K. Parui, S. Das, "Modelling and validation of loose coupler by using DGS in branch line coupler," J. of Radio Electronics., 11, (2012).

[20] M. Dydyk, "Accurate design of micro-strip directional couplers with capacitive compensation," Proc. of IEEE MTT-S Int. Microw. Symp. Dig., 581-584, (1990).

[21] I. Ohta, T. Kawai, T. Fujii, and Y. Kokubo, "Directivity enhancement of micro-strip coupled line couplers based on equivalent admittance approach," Proc. of IEEE MTT-S Int. Microw. Symp. Dig., 4346, (2003).

[22] C. S. Kim, J. S. Lim, D. J. Kim, and D. Ahn, "A design of single and multi-section micro-strip directional coupler with the high directivity,” Proc. of IEEE MTT-S Int. Microw. Symp. Dig., 1895-1898, (2004).

[23] S. Lee and Y. Lee, "An inductor-loaded micro-strip directional coupler for directivity enhancement," IEEE Microw. Wireless Compon. Lett., 19, 362-364, (2009).

[24] S. Lee and Y. Lee, "A design method for micro-strip directional couplers loaded with shunt inductors for directivity enhancement," IEEE Trans. Microw. Theory Tech., vol. 58, 994-1002, (2010).

[25] J. Muller and A. F. Jacob, "Complex compensation of coupler line structures in inhomogeneous media,” Proc. of IEEE MTT-S Int. Microwave. Symp. Dig., 1007-1010, (2008).

[26] K. Yamauchi, A. Inoue, and M. Miyazaki, "High directivity quarter wave micro-strip coupler with cancellation circuit of Wilkinson divider," Proc. of 38th Eur. Microwave. Conf., 195-198, (2008).

[27] S. Bensmida and F. M. Ghannouchi, "New high directivity coupler design using feed-forward compensation technique," Proc. of 38th Eur. Microw. Conf., 191-194, (2008).

[28] Y. H. Chun and J. S. Hong, "High directivity directional coupler using metamaterial," Proc. of 36th Eur. Microw. Conf., 329-331, (2006).

[29] P. H. Rao, J. Subramanian, and M. Kamki, "Miniaturized broadband micro-strip fractal rat-race coupler with shunt stubs," Microw. and Opt. Technol. Lett., 52, 289-292, (2010).

[30] M. Nosrati, B. Virdee "Realization of a compact branch-line coupler using quasi-fractal loaded coupled transmission-lines," Progress In Electromagnetics Research C, 33-40, (2010).

[31] M. Hayati and M. Nosrati, "Loaded coupled transmission line approach of left-handed (LH) structures and realization of a highly compact dualband branch-line coupler," Progress In Electromagnetics Research C, 10, 75-86, (2009).

[32] A. A. Ibrahim, A. M. E. Safwat, and H. E. Hennawy, "All planar compact size micro-strip CRLH arbitrary coupling directional coupler,” Microw. and Optical Technol. Lett., 55, 115-119, (2013).

[33] K. Yamamoto, H. Kurusu, S. Suzuki, and M. Miyashita, "High directivity enhancement with passive and active bypass circuit techniques for GaAs MMIC micro-strip directional couplers," IEEE Trans. on Microw. Theory And Techniques, 59, (2011).

[34] R. Islam and G. V. Eleftheriades, "Printed high-directivity metamaterial MS/NRI coupled-line coupler for signal monitoring applications," IEEE Microw. and Wireless Components Lett., 16, 164-166, (2006).

[35] A. Pourzadi, A. R. Attari, and M. S. Majedi, “A directivity enhanced directional coupler using epsilon negative transmission line," IEEE Trans. on Microw. Theory and Techniques, 60, (2012).

[36] S. Lee and Y. Lee, "A design method for micro-strip directional couplers loaded with shunt inductors for directivity enhancement," IEEE Trans. on Microw. Theory and Techniques, 58, 994-1002, (2010).

[37] CST Microwave Studio Version 12. 